\title{
The Characteristics of Gas-Water Two-Phase Radial Flow in Clay-Silt Sediment and Effects on Hydrate Production
}

\author{
Cheng Lu $\mathbb{D}^{1,2,3,4}$ Xuwen Qin $\mathbb{D}^{1,2,5,6}$ Lu Yu $\mathbb{D}^{1,2,5}$ Lantao Geng, ${ }^{1,2,5}$ Wenjing Mao $\mathbb{D}^{1,2,5}$ \\ Hang Bian ${ }^{(D)}{ }^{4,6}$ and Fanle Meng ${ }^{1,2,4}$ \\ ${ }^{1}$ Guangzhou Marine Geological Survey, China Geological Survey, Guangzhou 510760, China \\ ${ }^{2}$ Southern Marine Science and Engineering Guangdong Laboratory (Guangzhou), Guangzhou 511458, China \\ ${ }^{3}$ Center of Oil \& Natural Gas Resource Exploration, China Geological Survey, Beijing 100083, China \\ ${ }^{4}$ School of Energy Resources, China University of Geosciences, Beijing 100083, China \\ ${ }^{5}$ Gas Hydrate Engineering Technology Center, China Geological Survey, Guangzhou 510760, China \\ ${ }^{6}$ China Geological Survey, Beijing 100083, China
}

Correspondence should be addressed to Xuwen Qin; qinxuwen@163.com and Lu Yu; yzyulu@163.com

Received 31 December 2020; Revised 6 April 2021; Accepted 28 April 2021; Published 12 May 2021

Academic Editor: Jianhui Yang

Copyright $\odot 2021$ Cheng Lu et al. This is an open access article distributed under the Creative Commons Attribution License, which permits unrestricted use, distribution, and reproduction in any medium, provided the original work is properly cited.

\begin{abstract}
Many hydrate-bearing sediments in the Shenhu area of the South China Sea are featured with unconsolidated clayed silt, small particle size, and high content of clay, which can pose a great challenge for gas production. In order to investigate the gas-water relative permeability in clay-silt sediments, through a radial flow experiment, samples from the target sediment in the Shenhu area were selected and studied. The results show that the irreducible water saturation is high and the influence of the gas-water interaction is obvious. The relative permeability analysis shows that the two-phase flow zone is narrow and maximum gas relative permeability is below 0.1 . The flow pattern in clay-silt sediment is more complicated, and the existing empirical models are inadequate for flow characterization. The depressurization method to extract a hydrate reservoir with clay-silt sediments faces the problem of insufficient production capacity. Compared with the ordinary hydrate reservoir with sandstone sediment, the hydrate reservoir with clay-silt sediment has a low permeability and poor gas flow capacity. The gas-water ratio abnormally decreases during the production. It is urgent to enhance production with cost-effective measures.
\end{abstract}

\section{Introduction}

Gas hydrates are solid crystalline compounds and usually formed at low temperature and high pressure. Natural gas hydrate deposits vastly exist in the permafrost and subsea or deep ocean sediments [1]. In recent years, natural gas hydrate deposits with abundant reserves have been discovered in the northern part of the South China Sea and the eastern part of the Pearl River Mouth Basin [2]. More significantly, in 2020, a gas production pilot testing had been successfully conducted in the Shenhu region of the South China Sea operated by the China Geological Survey [3], in which over $86.14 \times 10^{4} \mathrm{~m}^{3}$ natural gas had been extracted during 30 days. This testing has strongly demonstrated the feasibility of a controllable gas extraction from hydrate- bearing sediments and provided a precious experience for future research and development.

Research shows that valuable natural gas hydrate reserves are considered mainly in coarse-grained sediments [4], and high abundance of hydrates, coinciding with sediments with large grain sizes, is usually accumulated in the turbidity current deposits and coarse sandstone formations [5]. These hydrate-bearing layers are featured with favorable porosity and permeability [6-8]. The average hydrate saturation in the Shenhu region of the South China Sea is over $20 \%$, with a maximum of $47.3 \%$. However, the core analysis demonstrated that hydrate reservoirs in the Shenhu region are typical clay-silt sediments with silt content up to $80-90 \%$ [9], which have poor bonding, high clay content, and low median diameter [10]. 
In the exploitation of the clay-silt hydrate reservoir, the generated gas and water from solid hydrate must flow through clay-silt porous medium and then into the production well. It is generally known that multiphase relative permeability is an important feature of porous medium flow characteristic, especially in hydrate reservoirs where gas and water coexist. With the decomposition edge extending, the gas-water flow characteristic of clay-silt sediments near the production well will determine the production capacity. Therefore, an accurate characterization of relative permeability behavior in a clay-silt hydrate reservoir has great significance for a sustainable gas production rate. Today, the research activities are actively targeting relative permeability of a common hydrate reservoir with sandstone. There are two different methods for the relevant study: theoretical method and experimental method.

Theoretical methods for modeling and simulating relative permeability in the hydrate-bearing formation have been developed for a long time. Singh et al. [11] derived analytical models to investigate relative permeability in hydrategas-water systems with an evenly distributed pore radius. Recently, Liu et al. [12] used fractal theory to describe pore structure of hydrate-bearing sediments and derived fractalbased models to study permeability and relative permeability. However, these models did not consider unconsolidated argillaceous siltstones, which have been shown to influence the properties of the hydrate reservoir in the South China Sea significantly.

Johnson et al. [13] conducted the experimental investigation of gas-water relative permeability for gas-hydratebearing sediments from the Mount Elbert Gas Hydrate Stratigraphic Test Well, Alaska North Slope. During two runs, nitrogen was used to displace water and the effective permeability of gas at irreducible water saturation was determined as a function of hydrate saturation. Moreover, unsteadystate relative permeability experiments produce piston-like displacement results suggesting that steady-state experiments might be preferable. Jarrar et al. [14] conducted a gas-water flow experiment with quartz sands containing kaolin, simulating the gas-water flow during hydrate extraction, and observed fine migration and fracture by means of a computed tomography scan. Experimental determination of relative permeability requires the sample undisturbed, which is a challenging task. It needs a precise control of pressure to ensure the maintenance of stable hydrodynamics and mechanical conditions, which is usually expensive and hard. Most scholars only studied the single-phase flow in the hydrate-bearing formations $[15,16]$. Konno et al. [17] analyzed the effective permeability of different hydrate-bearing sediments and found that effective stress change during exploitation can compact the unconsolidated sediment. Meanwhile, water produced by hydrate dissociation can change the salinity of stratum water, which may cause clay mineral expansion and permeability reduction.

However, there are few experiments on the flow characteristics of the clay-silt hydrate reservoir in the South China Sea. The hydrate-bearing sediments in the Shenhu region of the South China Sea are featured with unconsolidated argillaceous siltstones, which have high clay content and small sediment particle size. Accurate prediction and analysis of this type of sediments are an important foundation in effective and efficient exploitation of hydrate reservoirs. The gas-water flow experiment can truly reflect the transport situation of two-phase coexistence in the clay-silt sediments, and the relative permeability, irreducible water saturation, and residual gas saturation are closer to the field situation. So to that extent, a comprehensive research on flow characteristic of hydrate-bearing sediments with clay-silt formation is urgent.

In the early experiment of water flow in the clay-silt sediment core from the South China Sea, it is found that the permeability decreased gradually with the increase in differential pressure and this process is irreversible [18]. CT scanning was used to observe the phenomenon of pore volume creep in the sample during the flow process, and there was a clear power law relationship between the effective permeability and porosity of sediments under different pressure differences. It was worth noting that when the pressure gradient was less than $3 \mathrm{MPa} / \mathrm{m}$, the sediment pore deformation was not obvious. When the pressure gradient exceeded $3 \mathrm{MPa} / \mathrm{m}$, it had a great impact on the pore structure and the permeability decreases rapidly. In this paper, an experiment which discussed the two-phase flow pattern of gas and water in the clay-silt sediments was conducted. Moreover, the experimental results of two-phase flow in clay-silt sediments are combined to realize the simulation and production capacity evaluation of the hydrate reservoir with clay-silt sediments.

\section{Sample and Experimental Method}

2.1. Geological Background and Sample. The Shenhu region is located in the northern slope area of the South China Sea [19]. The experimental sample was obtained from the Shenhu region of the South China Sea. The particles were relatively fine, with a medium particle size of $12 \mu \mathrm{m}$. The main mineral components were quartz 53\%, carbonate $16 \%$, and clay minerals $26-30 \%$. The main components of clay minerals were montmorillonite and illite [20].

2.2. Experimental Equipment and Procedure. The experimental system of gas-water two-phase radial flow in clay-silt sediment is shown in Figure 1. The device is mainly composed of gas-water injection, overburden pressure, gas and water measurement, backpressure, and radial flow vessel. The radial flow vessel is the core of the device, which simulates a production well in the formation center. In the experiment, distilled water and nitrogen with a purity of $99.9 \%$ were used as an injection phase. The remaining experimental parameters are shown in Table 1.

The details of the experimental procedures are described as follows:

(1) Dry and triturate the sediment sample from the Shenhu region and fill it into the vessel with sandproof measures

(2) Samples were watered and compacted (Figure 2). The equipment was sealed up, and the overburden pressure was increased to simulate the formation pressure 


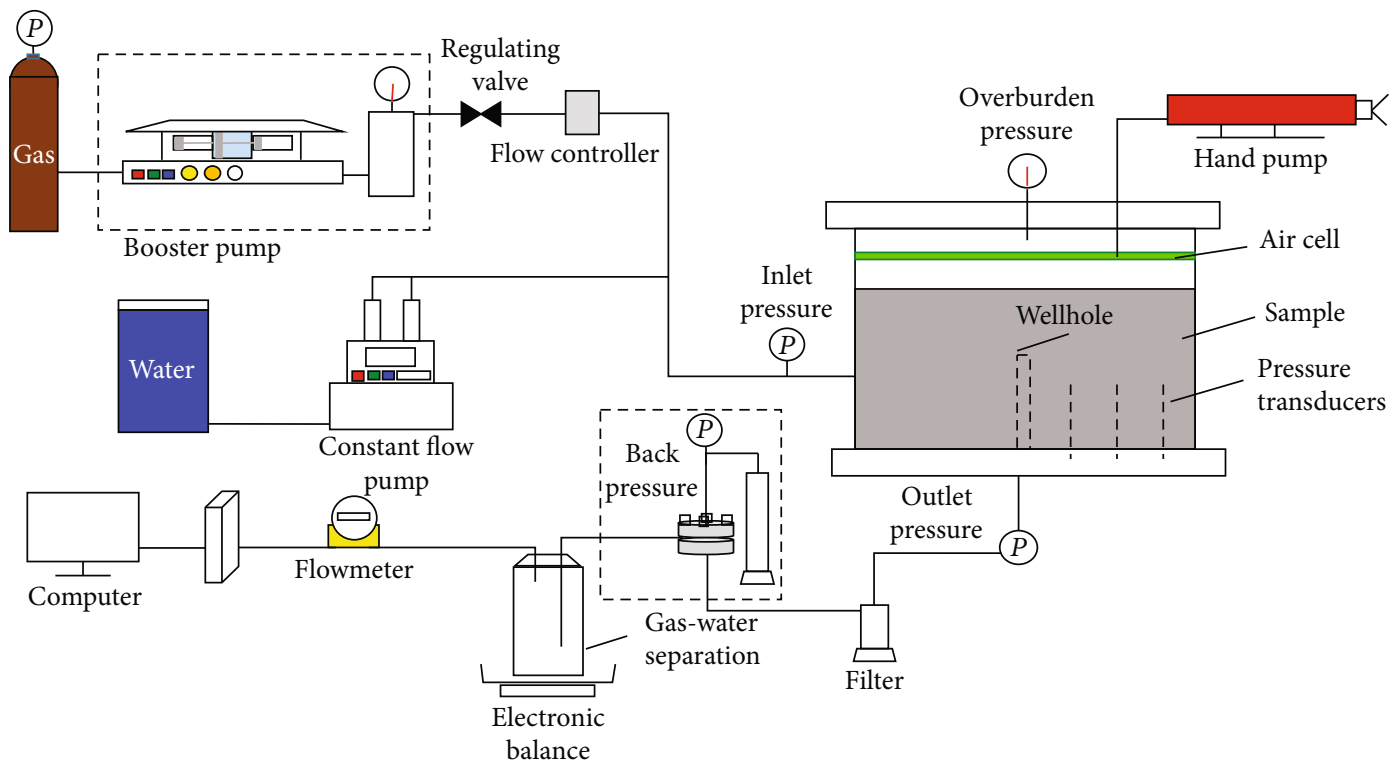

FIGURE 1: Experimental system.

TABLE 1: Experimental parameters.

\begin{tabular}{lccc}
\hline Parameter & Value & Parameter & Value \\
\hline$\mu_{\mathrm{w}}$-viscosity of the water at $20^{\circ} \mathrm{C}(\mathrm{mPa} \cdot \mathrm{s})$ & 1 & $\mu_{g}$-viscosity of the nitrogen at $20^{\circ} \mathrm{C}(\mathrm{mPa} \cdot \mathrm{s})$ & 0.0178 \\
$r_{e}$-sample radius $(\mathrm{cm})$ & 14.5 & $r_{\mathrm{w}}$-well radius $(\mathrm{cm})$ & 1.3 \\
$h$-well height $(\mathrm{cm})$ & 7 & $P_{e}$-inlet pressure $\left(10^{-1} \mathrm{MPa}\right)$ & Experimental value \\
$P_{\mathrm{w}}$ - outlet pressure $\left(10^{-1} \mathrm{MPa}\right)$ & Experimental value & $Q_{\mathrm{w}}$-flow rate of water $\left(\mathrm{cm}^{3} / \mathrm{s}\right)$ & Experimental value \\
$Q_{g}$-flow rate of nitrogen $\left(\mathrm{cm}^{3} / \mathrm{s}\right)$ & Experimental value & & \\
\hline
\end{tabular}

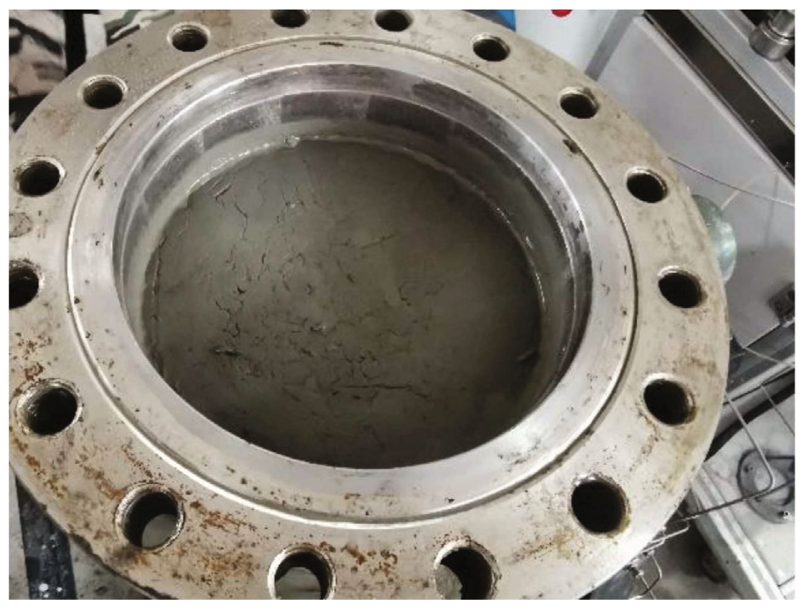

Figure 2: Compacted sample.

and ensure the similar degree of sample compaction. In the experiment, the overburden is usually set at $15 \mathrm{MPa}$. After that, the sample was saturated with water. The sample pore volume and porosity are calculated according to

$$
\begin{gathered}
V_{\mathrm{p}}=V_{t}-\frac{m_{0}}{\rho_{0}}, \\
V_{t}=\pi r_{e}^{2} h_{m}-\pi r_{\mathrm{w}}^{2} h, \\
\phi=\frac{V_{\mathrm{p}}}{V_{t}} \times 100 \%,
\end{gathered}
$$

where $V_{p}$ is the pore volume $\left(\mathrm{cm}^{3}\right) ; V_{t}$ is the sample volume $\left(\mathrm{cm}^{3}\right) ; h_{m}$ and $h$ are the sample height and well length $(\mathrm{cm})$, respectively; $m_{0}$ is the dry sample weight $(\mathrm{g}) ; \rho_{0}$ is the dry sample density $\left(\mathrm{g} / \mathrm{cm}^{3}\right)$. The measured value is $2.6 \mathrm{~g} / \mathrm{cm}^{3}$.

(3) The gas and water were injected into the sample at a constant rate according to a certain flow ratio. The inlet and outlet pressure was measured. The gas and water flow rate was measured. Then, calculate the effective permeability of gas and water and the water saturation of the sample. Sample water saturation measurement methods included the weighing method, material balance method, and resistivity method. In this experiment, the material balance method was used because of the large sample size. It was expressed as 


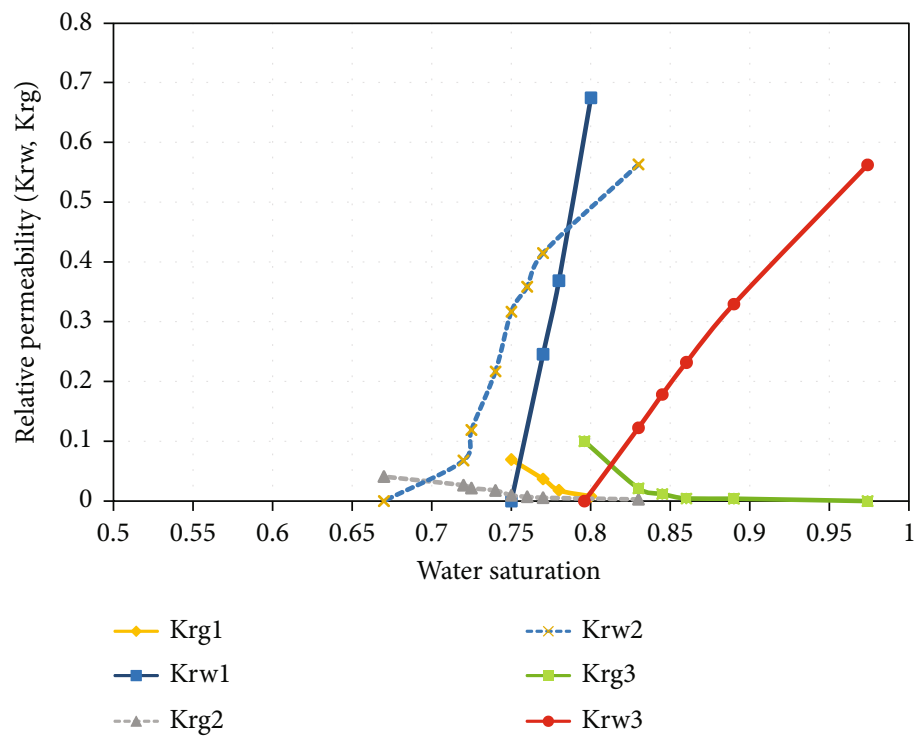

FIGURE 3: Relative permeability curve of different samples.
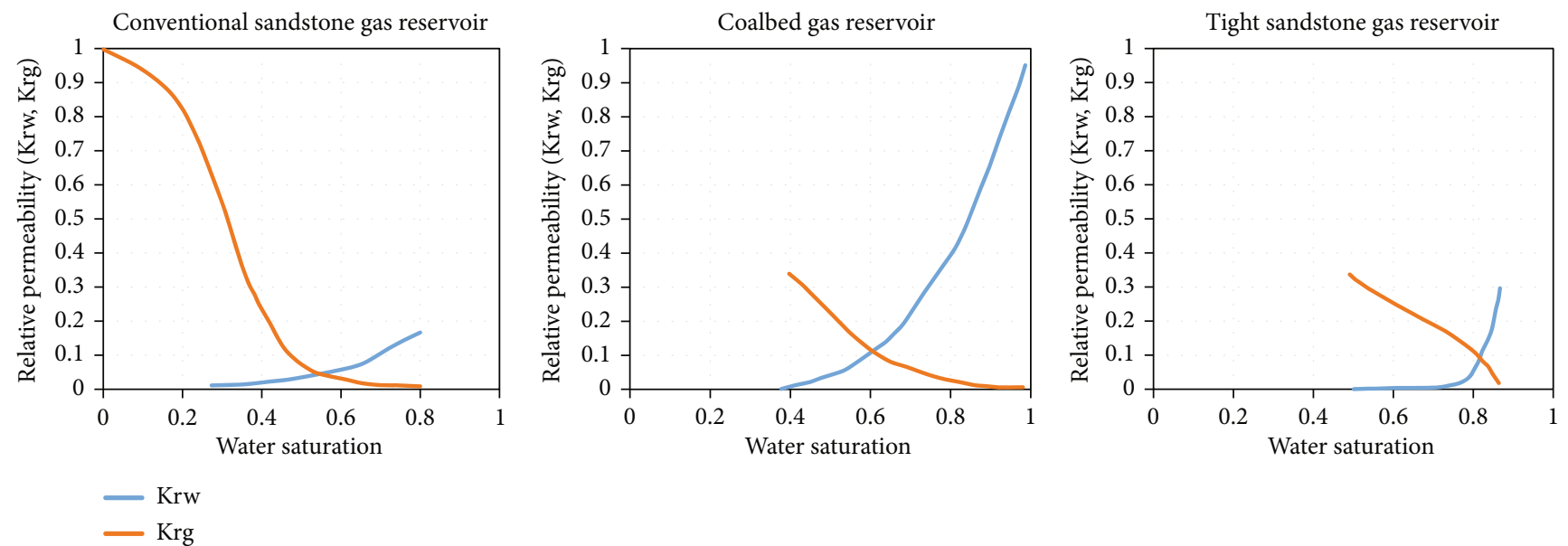

FIGURE 4: Relative permeability curve of other gas reservoirs.

$$
S_{j}=S_{t j}+\frac{V_{c} f_{j}-V_{c j}}{V_{\mathrm{p}}},
$$

where $S_{j}$ and $S_{t j}$ are the saturation of the $j$-phase at the present test point and the previous test point, respectively; $V_{c}$ is the total injection volume $\left(\mathrm{cm}^{3} / \mathrm{s}\right) ; f_{j}$ is the proportion of the $j$-phase in the total injection volume; $V_{c j}$ is the total volume of the $j$-phase in the outlet $\left(\mathrm{cm}^{3}\right) ; V_{p}$ is the pore volume $\left(\mathrm{cm}^{3}\right)$.

Therefore, as long as the water flow rates of the inlet and outlet are accurately recorded, the fluid saturation in the sample at the corresponding test point can be calculated.

(4) In the experiment, decrease the water injection rate and increase the gas injection rate gradually. Repeat the above procedure, and gas-water relative permeability with different water saturation can be obtained. In the experiment, the pressure gradient of the sample must be kept less than $3 \mathrm{MPa} / \mathrm{m}$.

\section{Experimental Results and Discussion}

This experiment tested three sets of clay-silt sediment samples. The permeability of sample 1 is $0.274 \mathrm{mD}$. The permeability of sample 2 is $0.481 \mathrm{mD}$. The permeability of sample 3 is $0.213 \mathrm{mD}$. The relative permeability curve of gas and water with different permeability samples are shown in Figure 3.

Figure 4 shows the relative permeability curves of three other gas reservoirs [21-23]. As shown from the relative permeability curve of the conventional sandstone gas reservoir, irreducible water saturation is low. It also reveals that, with the water saturation increasing, the gas relative permeability decreases slowly and the water relative permeability increases relatively slowly. Overall, the fluid flow capacity of the conventional sandstone gas reservoir is good. In the exploitation 

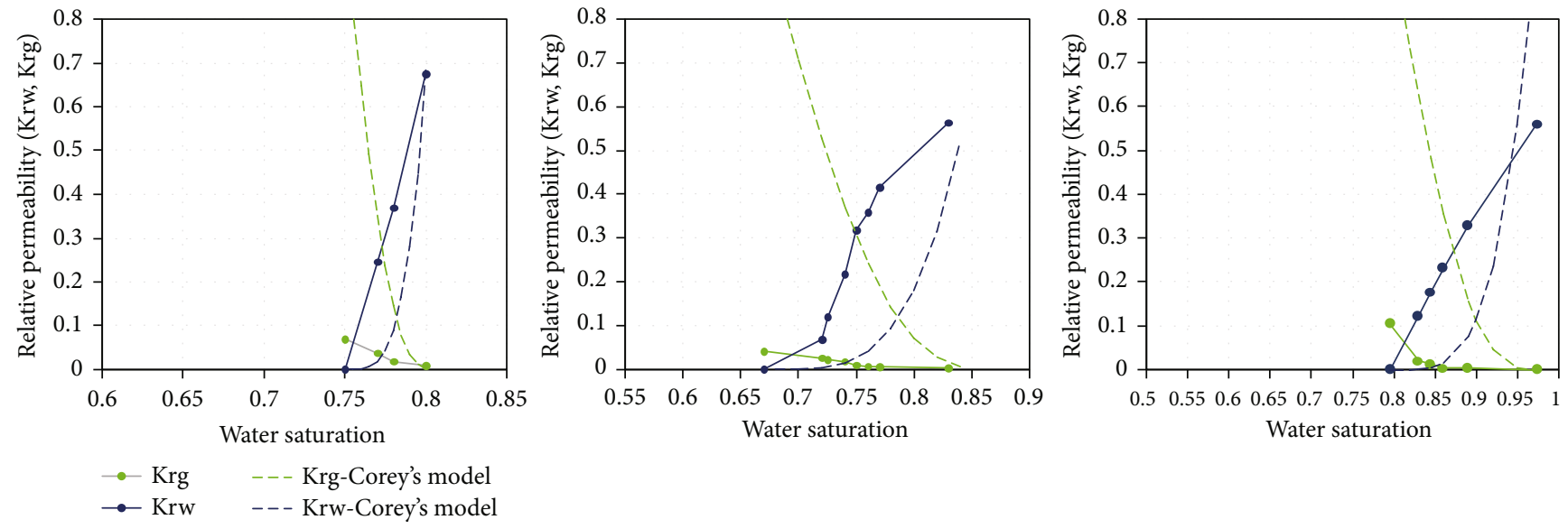

FIgURE 5: The comparison between experimental results and Corey's empirical formula.

of this type of gas reservoir, water content rises slowly and the stable production cycle is long. In the coalbed gas reservoir, the irreducible water saturation is greater. With the increase in water saturation, the water relative permeability increases rapidly. For the tight sandstone gas reservoir, the irreducible water saturation is very high. The gas relative permeability under the irreducible water saturation is low. With the water saturation rising, the gas relative permeability rapidly decreases in a straight line form. The water relative permeability initially rises slowly and rises rapidly after a turning point. The isotonic point is deviation to the right. The flow capacity of the tight sandstone gas reservoir is weak.

By comparison, it can be found that, in the gas-water relative permeability curve of the clay-silt sediment, the irreducible water saturation is much higher than that of other reservoirs, which is determined by the high clay content of the clay-silt sediment [24]. It also directly determines that the mobile gas porosity in the clay-silt sediment is very low. The two-phase flow area is unusually narrow, and the maximum gas relative permeability, less than 0.1 , is very low. These characteristics are closely related to the permeability, mobile fluid porosity, pore-throat structure, and clay content of the clay-silt sediment [25]. To some extent, the maximum gas relative permeability also reflects the difficulty in extracting this type of hydrate reservoir.

For the porous system composed of water, gas, and claysilt sediment, water is a strong wetting phase [6]. Gas is a nonwetting phase. The three sets of the relative permeability curve are generally the same, but the values of the feature points are different, which are determined by the pore structure characteristics of the samples. From the curve, it can be seen that the lower the absolute permeability of the sample, the greater the irreducible water saturation is. It is because the pore-throat structure of the sample with low permeability is smaller and more complex. The capillary pressure is greater, and water is difficult to drive.

Although the different samples have different permeability, the flow characteristics are similar. Initially, there is more water than gas, due to the hydrophilic sediment, there exists

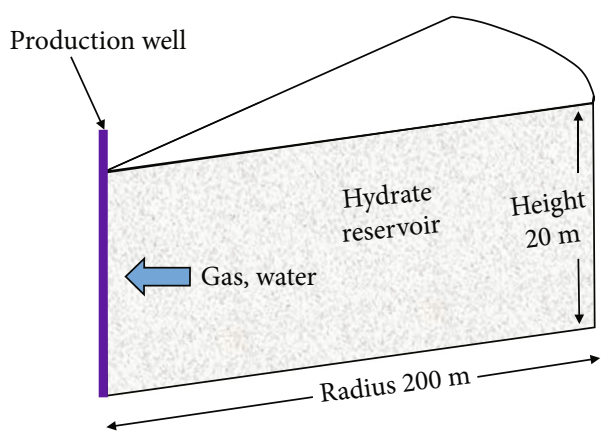

Figure 6: Schematic model of the methane hydrate production scenario.

water film/water ring/water bridge on the pore wall, and the distribution is very uneven. There also exists the irreducible water in the small pore. Because of the great capillary resistance, the gas has difficulty entering the small pore. The gas can only flow along the center of the wide throat in limited quantities. At this time, the flow pattern of gas and water is mainly like "water-packed gas" and the relative permeability of the gas is very low [26]. It can be seen from Figure 3, with the increase in gas saturation, the interference between gas and water is more serious and the water relative permeability decreases rapidly. This is because the main flow channel-large throat channel-is gradually occupied by gas and free water content decreased. However, the gas permeability does not rise significantly. The remaining water in the sample is distributed in a ring-like form on the surface of the particles or at the corner of the particles, which seriously affects the flow capacity of the gas phase. At last, the gas saturation increases and the number of gas clusters (uneven distribution of gases, cluster distribution) in the sample rises. The "Jamin effect" on gas flow is increased. Therefore, under the irreducible water saturation, the relative permeability of the gas phase is not high.

In the previous study that was aimed at numerical simulation of hydrate development, the relative permeability model usually adopted the empirical formula. Corey's model 
TABLE 2: Parameters of hydrate-bearing formations.

\begin{tabular}{lccc}
\hline Parameter & Value & Parameter & Value \\
\hline Hydrate saturation & 0.3 & Initial water saturation & 0.7 \\
Porosity & 0.35 & Permeability $(\mathrm{mD})$ & Experimental value \\
Relative molecular mass of hydrate $(\mathrm{g} / \mathrm{mol})$ & 119.54 & Density of hydrate $\left(\mathrm{kg} / \mathrm{m}^{3}\right)$ & 919.7 \\
Specific heat of hydrate $\left(\mathrm{J} /\left(\mathrm{m}^{3} \cdot \mathrm{K}\right)\right)$ & $1.47 \times 10^{6}$ & Heat conduction coefficient of hydrate $(\mathrm{J} /(\mathrm{m} \cdot \mathrm{d} \cdot \mathrm{K}))$ & $4.58 \times 10^{4}$ \\
Specific heat of formation $\left(\mathrm{J} /\left(\mathrm{m}^{3} \cdot \mathrm{K}\right)\right)$ & $8 \times 10^{5}$ & Heat conduction coefficient of formation $(\mathrm{J} /(\mathrm{m} \cdot \mathrm{d} \cdot \mathrm{K}))$ & $1.5 \times 10^{5}$ \\
\hline
\end{tabular}

is listed as follows, which is widely used in the tough+hydrate simulator [27].

$$
\begin{gathered}
k_{r l}=S^{4}, \\
k_{r g}=(1-S)^{2}\left(1-S^{2}\right),
\end{gathered}
$$

where $S=\left(S_{l}-S_{l r}\right) /\left(1-S_{l r}-S_{g r}\right)$

To demonstrate the applicability of the common empirical model to clay-silt formations, the comparison between experimental results and Corey's empirical formula has been illustrated in Figure 5. As clearly shown in Figure 5, the fitting result is poor. In the empirical model, with the water saturation decreasing, the water relative permeability drops more rapidly. Meanwhile, the gas relative permeability rockets upwards. It is notable that the gas relative permeability at the irreducible water saturation is greatly high, which is similar to the flow characteristics in the conventional sandstone gas reservoir.

It is concluded that the flow pattern in clay-silt sediment is more complicated and the existing empirical models are inadequate for flow characterization. However, the way to obtain an empirical equation of the relative permeability curve in clay-silt formation through the experimental method still faces some difficulties, such as standardization of sample preparation and instrument precision. More standardized experiments should be conducted. Seeing the lack of empirical equation, one of the relative permeability curves from the experimental results will be used in the following numerical simulation.

\section{Numerical Simulation}

In order to study the effect of flow characteristics of clay-silt sediment on the production capacity of hydrate reservoir with clay-silt sediments, numerical simulation software (CMG STARS) has been used. The hydrate reaction kinetics is set by partial equilibrium reaction. The experimental results of two-phase flow of clay-silt sediments are combined to realize the simulation and production capacity evaluation of the hydrate reservoir with clay-silt sediments.

4.1. Model Parameters for a Real Case Study. A numerical simulation model based on the multiphase flow characteristics described above and the geological parameters of hydrate-bearing sediments in the Shenhu region in the South China Sea was built. It can be seen from Figure 6 that a twodimensional radial homogeneous model is established to

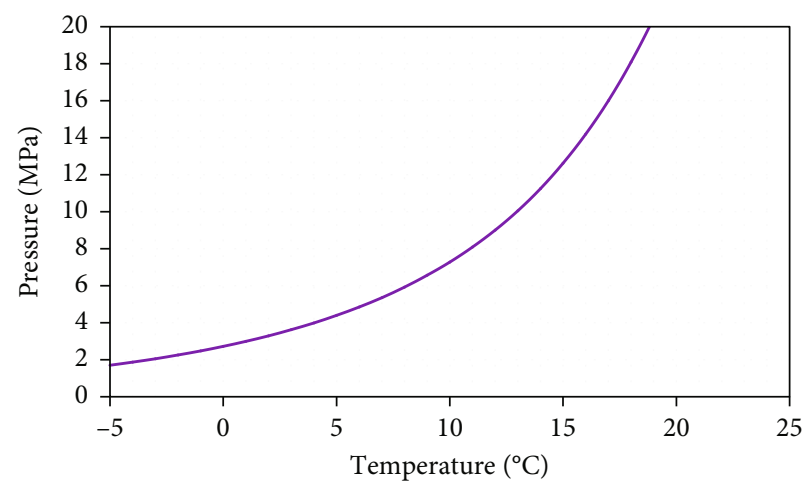

FIgURE 7: Phase equilibrium curve of methane hydrate.

simulate a depressurized well in the center of the hydrate reservoir with clay-silt sediments.

Suppose that a shallow methane hydrate reservoir with clay-silt sediments is located $200 \mathrm{~m}$ below the mud line. The sea is $1000 \mathrm{~m}$ deep. The reservoir pressure is $12.13 \mathrm{MPa}$, and the temperature is $15.15^{\circ} \mathrm{C}$. The whole model grid is $200 \mathrm{~m} \times 20 \mathrm{~m}$. The main properties of the simulated hydrate-bearing sediment are listed in Table 2. For seawater and porous media used in this investigation, Figure 7 can determine the equilibrium state of hydrate. The above experimental result of sample 1 has been used for the relative permeability model.

Radial mesh and local grid refinement (Figure 8) are used in order to explore the mobility of two phases near the straight well and consider the convergence and running speed of the model. The production well is operated at a constant pressure of $4 \mathrm{MPa}$ at the bottom of the wellbore. The production period is 1 year.

4.2. Simulation Results. The performance of gas production up to 1 year is shown in Figure 9. As shown, the gas rate reaches their peaks $\left(2960 \mathrm{~m}^{3} / \mathrm{d}\right)$ in the early stage rapidly and then decreases to $2300 \mathrm{~m}^{3} / \mathrm{d}$ and eventually fluctuates at a stable state in a long term. The ultimate cumulative gas production after 1 year is $8.36 \times 10^{5} \mathrm{~m}^{3}$. Figure 10 shows the water production in 1 year. It is notable that the water production rate drops from $25 \mathrm{~m}^{3} / \mathrm{d}$ initially to around $21 \mathrm{~m}^{3} / \mathrm{d}$ at the 50th day and then slowly rises to $22.4 \mathrm{~m}^{3} / \mathrm{d}$ at the end of the simulation.

In the middle and late production stage of the conventional sandstone hydrate reservoir, with the extension of the decomposition edge, the gas production rate continues to rise and water production declines continuously, which also 


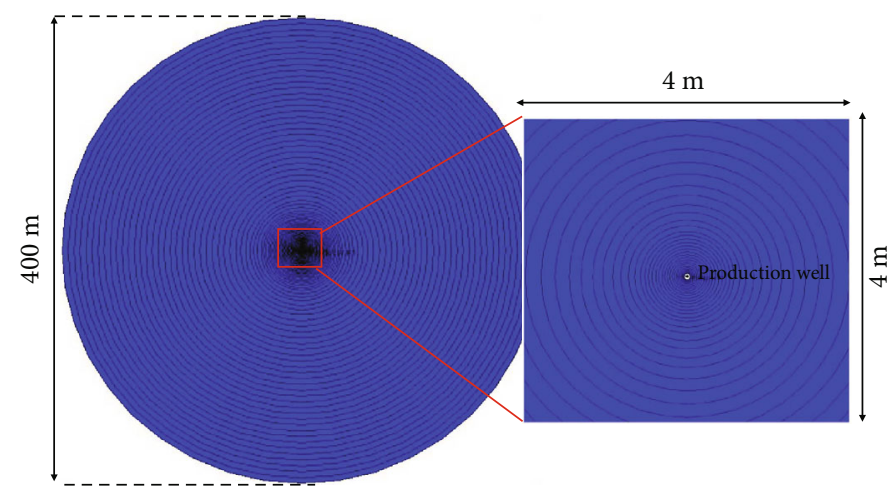

FIgURE 8: Mesh generation and local grid refinement.

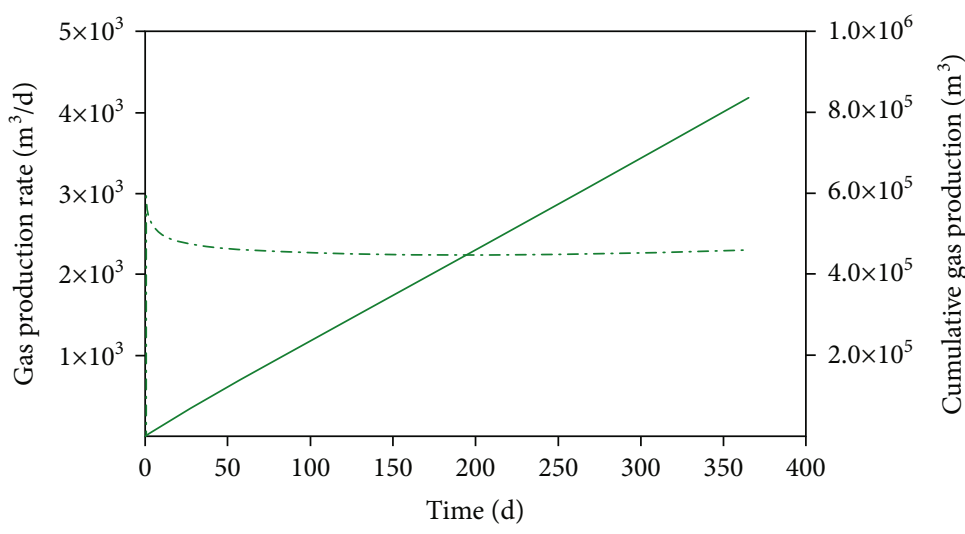

.... Gas production rate

- Cumulative gas production

FIgURE 9: Performance of gas production.

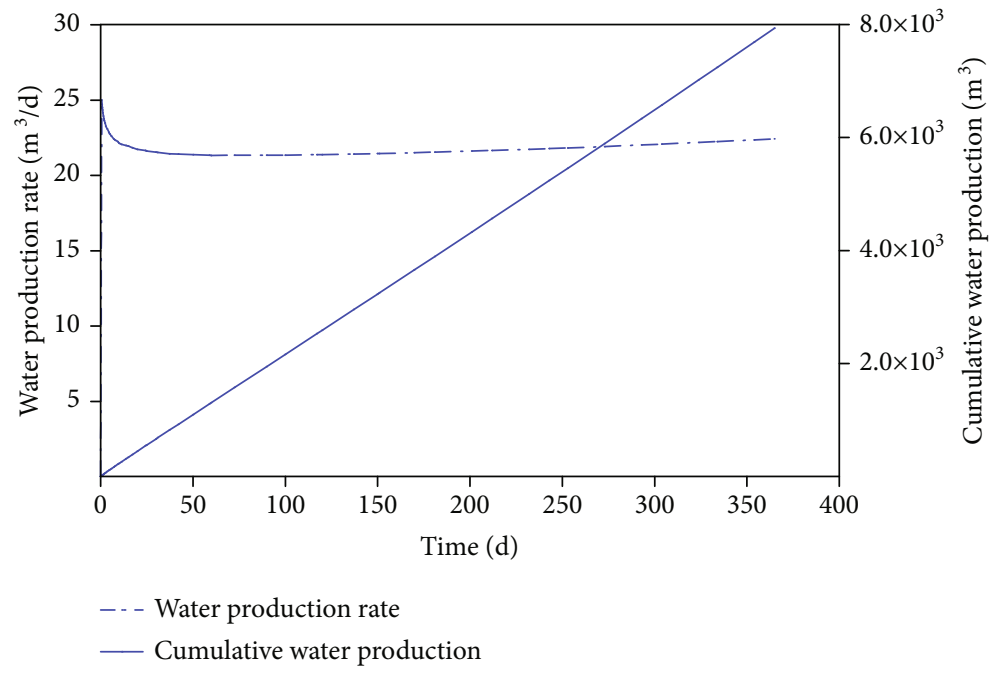

Figure 10: Performance of water production.

means that the instantaneous gas-water ratio will decline. However, the simulation results based on the two-phase flow characteristic of clay-silt sediments are different from that of conventional sandstone hydrate reservoirs. The gas production rate cannot rise rapidly, and the water production rate is high. The instantaneous gas-water ratio (Figure 11) slides from the initial 118 to 102 at the end of the simulation. Some criteria will be used to evaluate the technical feasibility of gas production from an unconsolidated argillaceous siltstone hydrate reservoir, including sufficiently high gas production rate and relatively high gas-to-water ratio. Considering the complexity and high cost of deepwater operations, it is 


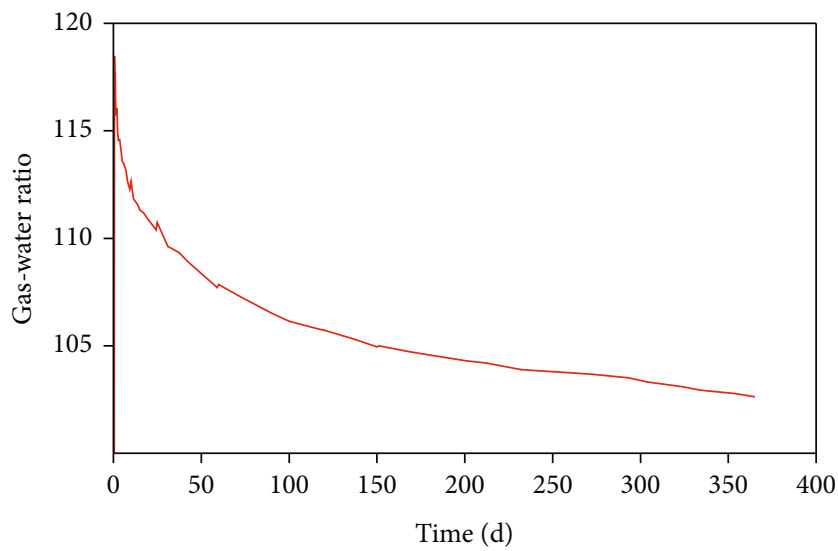

_ Gas-water ratio

Figure 11: Performance of the gas-water ratio.

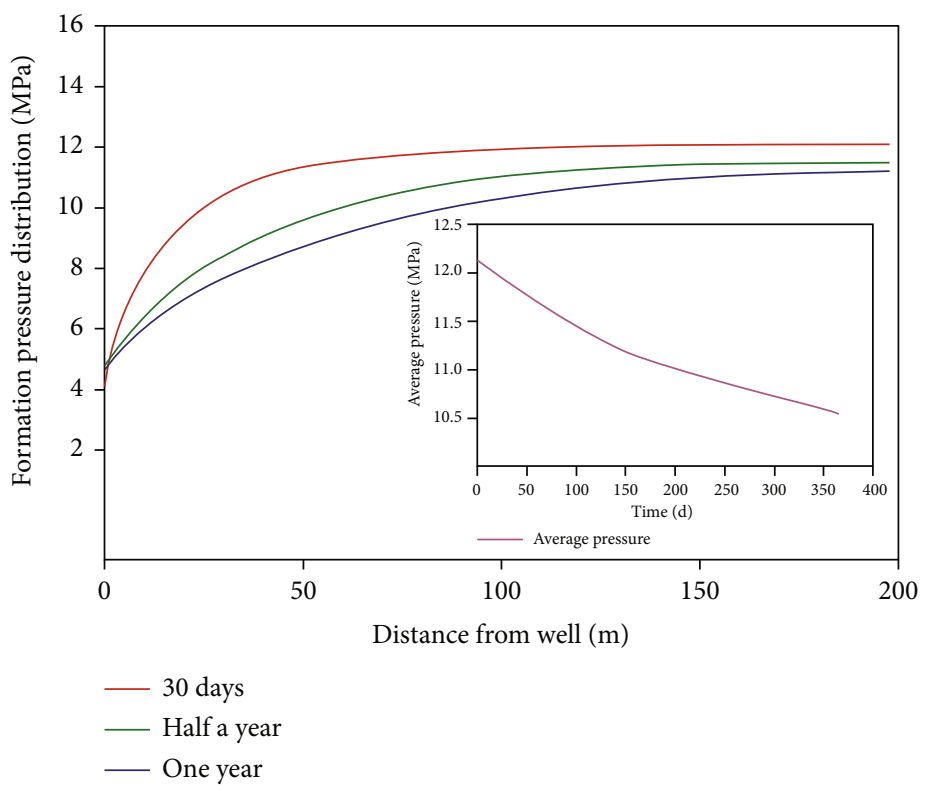

FIGURE 12: The distributions of pressure and average formation pressure at different times.

generally believed that the daily gas production of deepwater gas wells needs to exceed $2.5 \times 10^{5} \mathrm{~m}^{3} / \mathrm{d}$ and the water production is controllable. From this point of view, production capacity of the hydrate reservoir with clay-silt sediments using a single depressurization method cannot achieve economic feasibility.

The distribution evolution of temperature and pressure in the reservoir can also react with the production conditions of the hydrate reservoir. The variations of the formation pressure after 30 days, half a year, and 1 year are plotted in Figure 12. As can be seen from the figure, the pressure diffusion is slow and the average formation pressure decreases by only $13 \%$ (to $10.55 \mathrm{MPa}$ ) in 1 year. The rate of pressure drop decreases gradually. The reason is that the irreducible water saturation in the hydrate reservoir with clay-silt sediments is too great. The mobile water saturation is low, and the formation water cannot be driven effectively, resulting in the slow pressure diffusion. The variations of the formation temperature after 30 days, half a year, and 1 year are plotted in Figure 13. Hydrate dissociation is an endothermal reaction that absorbs enough heat from surrounding fluid and formation. As revealed, the reservoir temperature dropped rapidly to less than $7^{\circ} \mathrm{C}$ on the 30th day, due to the hydrate dissociation near the well. During the production, the lowtemperature edge continued to extend, but the advance speed is low. In the end of the simulation, the low-temperature edge only advanced to $5 \mathrm{~m}$ from the well.

In the process of hydrate extraction, the reservoir is usually divided into three parts: the dissociated zone, the dissociating zone, and the stable zone. The variations of the hydrate saturation after 30 days, half a year, and 1 year are plotted in Figure 14. It can be seen that the front edge of the dissociated zone advances very slowly. The edge is located $1.4 \mathrm{~m}$ from the well at 30 days and only $4.7 \mathrm{~m}$ at the end of the simulation. 


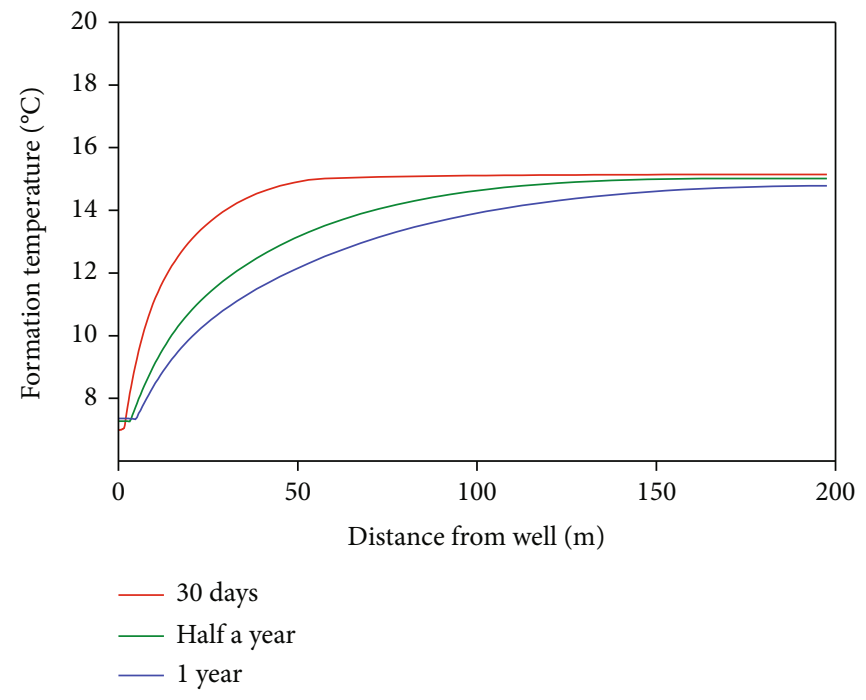

FIgURE 13: The distributions of temperature at different times.

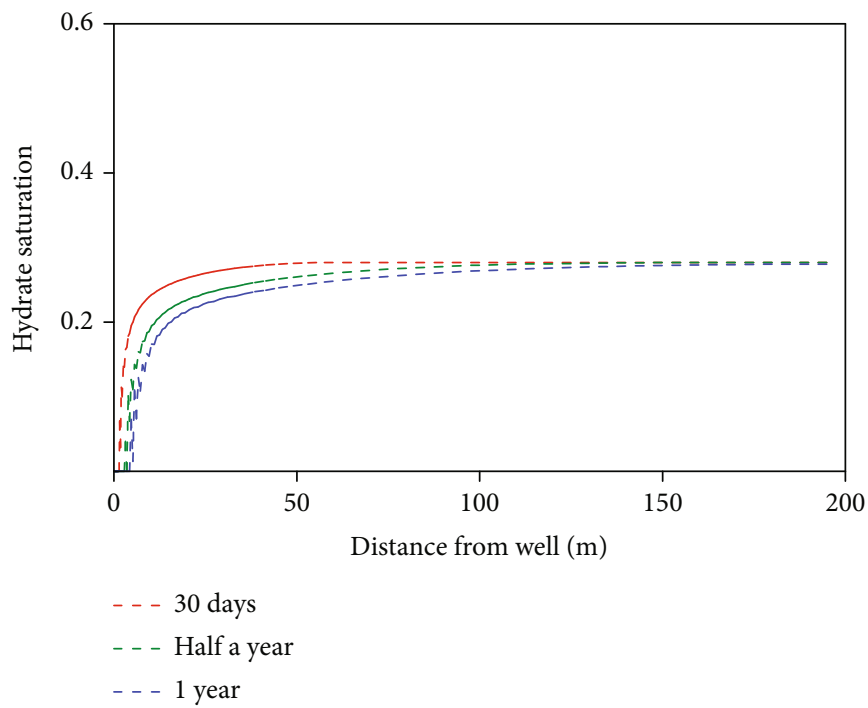

FIGURE 14: The distributions of hydrate saturation at different times.

The front edge of the dissociating zone advances faster, but the dissociation rate of hydrate in this zone is slow and the saturation of hydrate decreases slowly.

It is assumed that no creep deformation occurs in the sediment during extracting the pore structure and porosity does not change and the space is fully occupied by the water and methane gas from dissociated hydrate. The variations of the water and gas saturation are plotted in Figure 15. As revealed, gas and water saturation with different distances from the well increases with the dissociation of hydrate, but the water saturation increased by a small margin. The water saturation in the dissociated zone increased from 0.7 to 0.76 , while the gas saturation increased to 0.24 from the initial value, forming a high gas saturation zone near the well. Combined with the production curve, it can be found that the formation of a high gas saturation zone near the well does not lead to a significant increase in gas production. Figure 16 shows the variations of the water and gas relative permeability $1 \mathrm{~m}$ from the well. It can be found from the figure that the water saturation rises, with an increase of $8.6 \%$, from 0.7 to 0.76 within 20 days. But the relative permeability of the water phase increased by $800 \%$. Although the gas saturation increased from the initial value to 0.238 , the relative permeability of the gas phase was still less than 0.01 . The same situation can be seen from Figures 17 and 18, which are the changes of the water-gas relative permeability $5 \mathrm{~m}$ and $10 \mathrm{~m}$ from the well. The low relative permeability of gas means that the gas flow capacity is poor. The dissociated gas cannot flow smoothly into the well, and a lot of them stay in the formation.

Figure 19 is a comparison between the gas volume from the dissociated hydrate and the output gas volume from the 

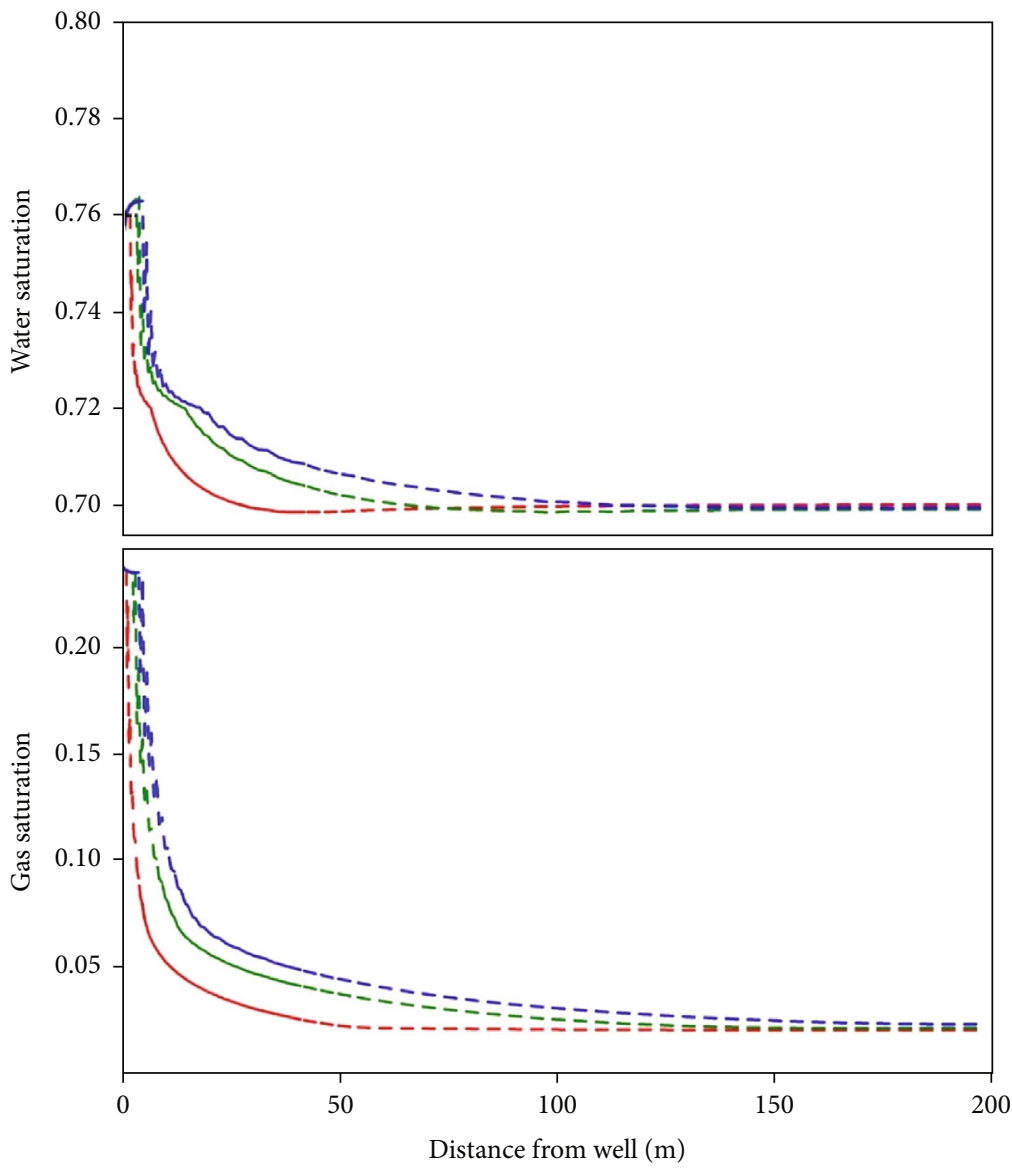

$$
\begin{aligned}
& \text { - - } 30 \text { days } \\
& \text { - - Half a year } \\
& \text { - - } 1 \text { year }
\end{aligned}
$$

Figure 15: The distributions of water saturation and gas saturation at different times.

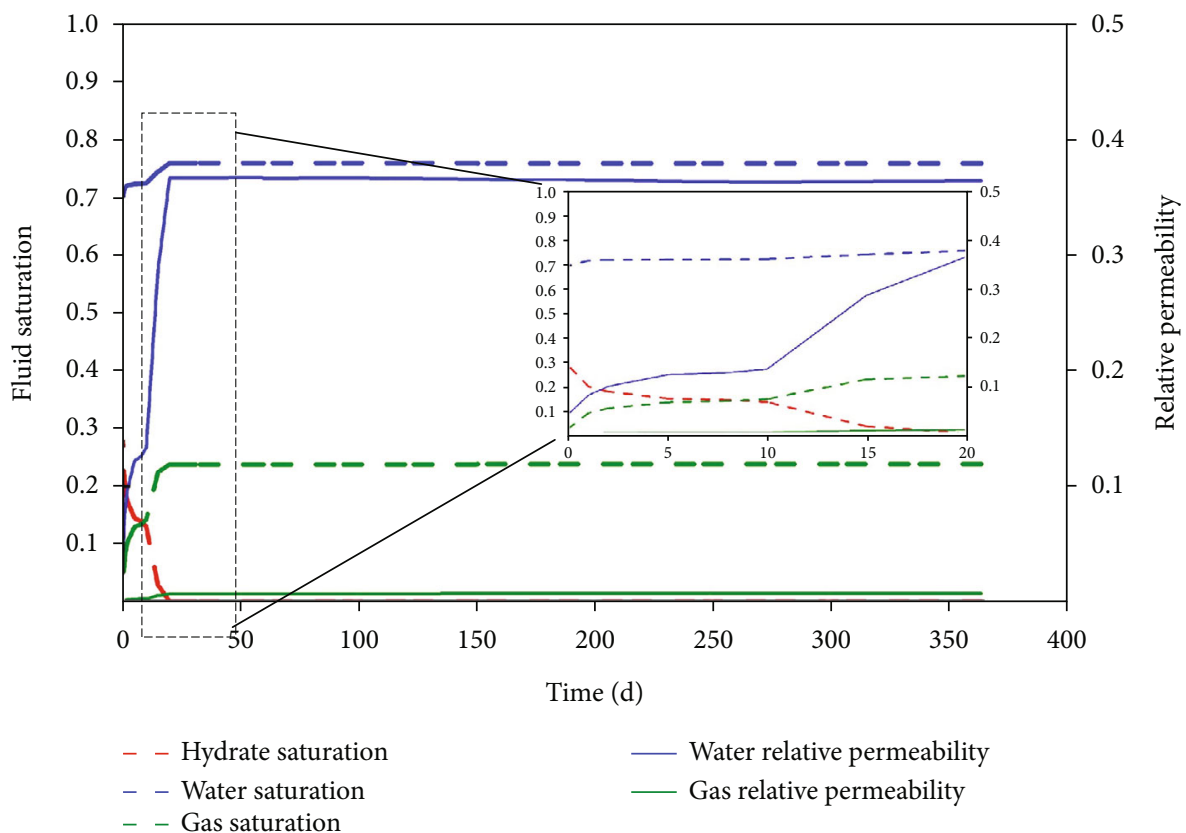

FIgURE 16: The variations of the water and gas relative permeability $1 \mathrm{~m}$ from the well. 


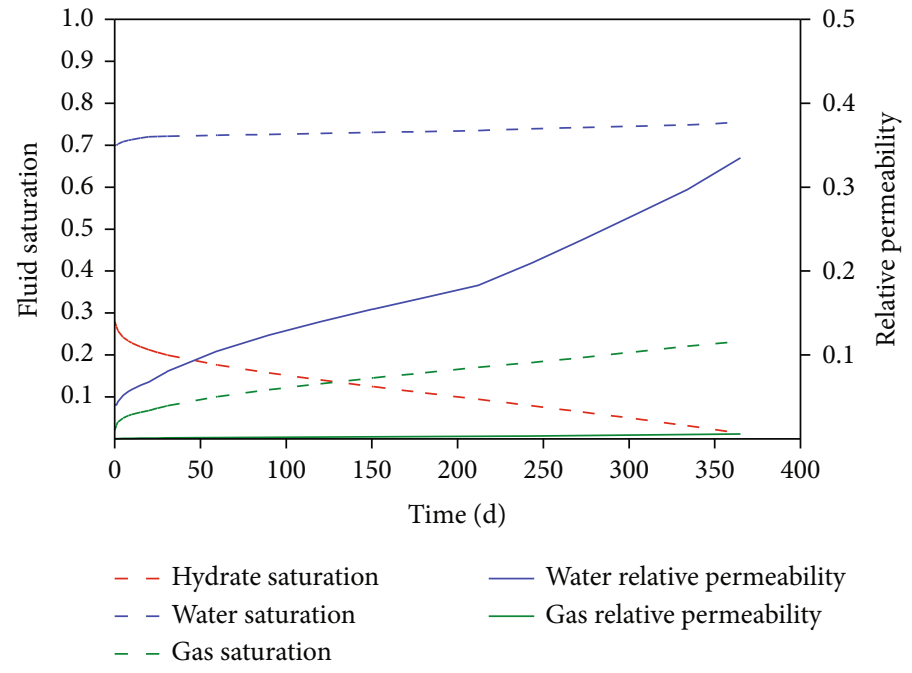

Figure 17: The variations of the water and gas relative permeability $5 \mathrm{~m}$ from the well.

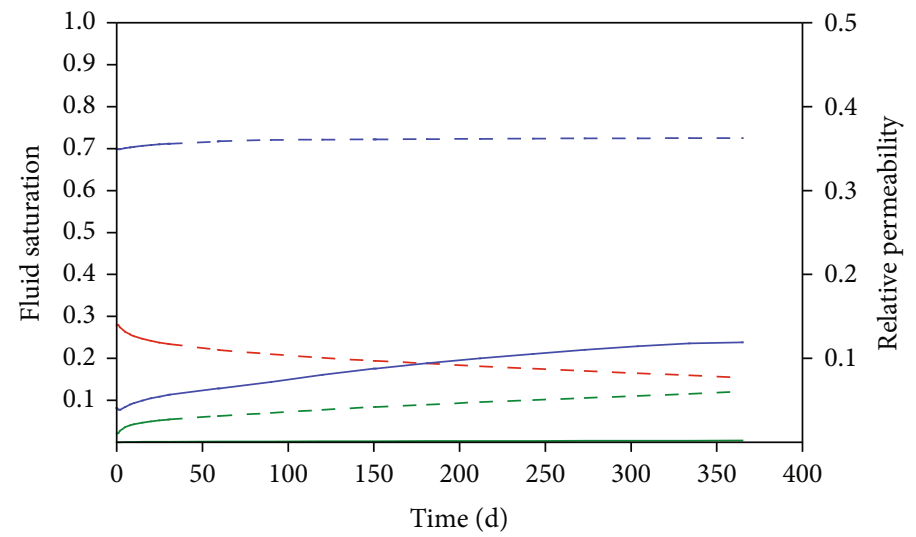

$$
\begin{array}{ll}
\text { - }- \text { Hydrate saturation } & \text { - Water relative permeability } \\
\text { - }- \text { Water saturation } & \text { Gas relative permeability } \\
\text { - }- \text { Gas saturation } &
\end{array}
$$

FIgURE 18: The variations of the water and gas relative permeability $10 \mathrm{~m}$ from the well.

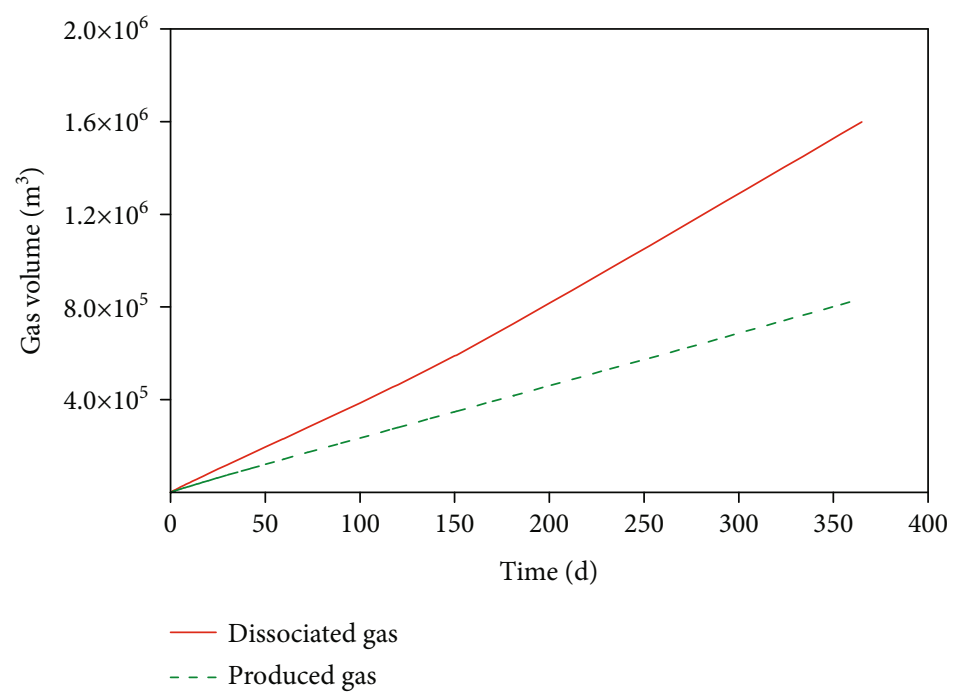

FIGURE 19: The comparison between the gas volume from the dissociated hydrate and the output gas volume from the well. 


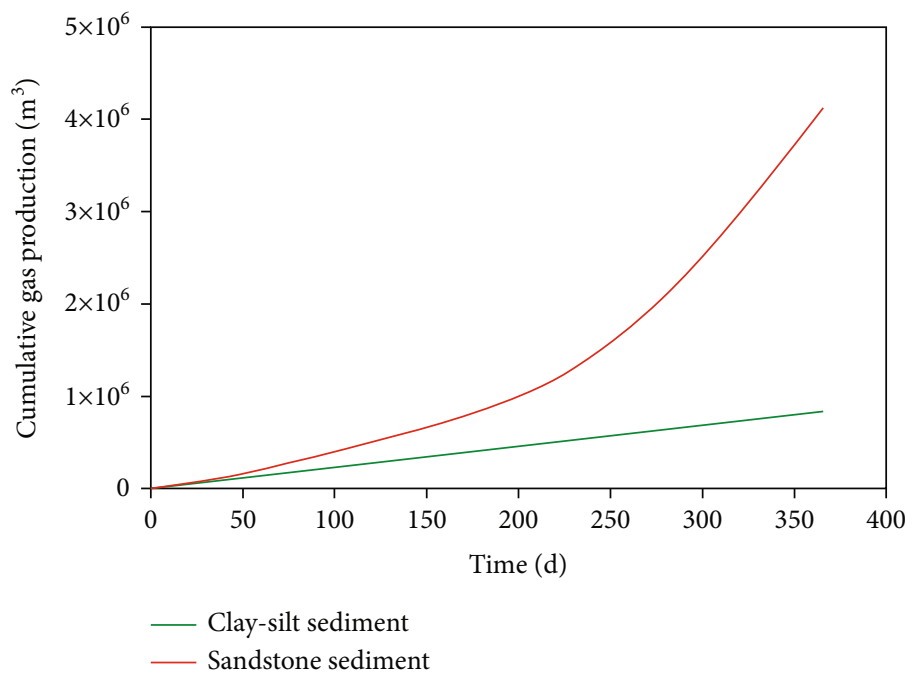

FIgURE 20: The comparison of cumulative gas production.

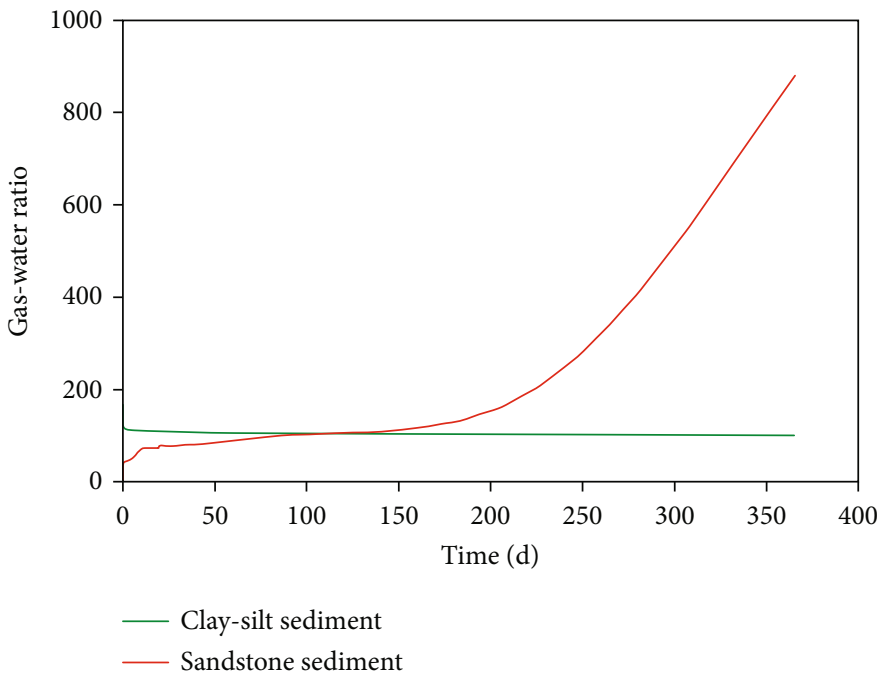

Figure 21: The comparison of the gas-water ratio.

well. It can be clearly seen that the dissociated gas is much greater than the gas produced from the well. At the end of the simulation, the dissociated gas volume is nearly $1.6 \times$ $10^{6} \mathrm{~m}^{3}$, but the produced gas volume is only half of the dissociated gas volume.

Compared with the ordinary hydrate reservoir with sandstone sediment, the hydrate reservoir with clay-silt sediment has a low permeability and poor flow capacity. In other simulation conditions, it can be seen from Figures 20 and 21 that the production capacity of the sandstone formation is nearly 5 times that of the clay-silt sediment. The gas-to-water ratio of sandstone formation can increase to nearly 900. In summary, it can be found that the depressurization method to extract the hydrate reservoir with clay-silt sediments faces the problem of insufficient production capacity. It is urgent to enhance production measures, such as thermal stimulation and hydrofracturing.

\section{Conclusion}

(1) The hydrate-bearing sediments in the Shenhu region of the South China Sea are featured with unconsolidated argillaceous siltstones, which have high clay content and small sediment particle size. Its irreducible water saturation is more than 0.65 . The pore of mobile gas is small, and the interference between gas and water is strong

(2) Clay-silt sediment has a poor permeability. The twophase flow area is unusually narrow, and the maximum gas relative permeability, less than 0.1 , is very low. These characteristics are closely related to the permeability, mobile fluid porosity, pore-throat structure, and clay content of the clay-silt sediment. The flow pattern is complicated, and many 
mechanisms have been inferred in the paper. Of course, the gas-water flow mechanisms in clay-silt sediment will be more persuasive with the help of microscopic visual experiments

(3) The fitting result between experimental results and Corey's empirical formula is poor. That means that the existing empirical models are inadequate for flow characterization in the hydrate reservoir with clay-silt sediments

(4) The depressurization method to extract the hydrate reservoir with clay-silt sediments faces the problem of insufficient production capacity. The front edge of the dissociated zone advances very slowly. Half of the dissociated gas cannot flow into the well, and the gas-water ratio decreases during the production because of the weak flow capacity of methane. It is urgent to enhance production with cost-effective measures

\section{Data Availability}

If the readers request the raw data, they can contact the corresponding author via e-mail. The e-mail is yzyulu@163.com.

\section{Conflicts of Interest}

The authors declare that they have no conflicts of interest.

\section{Acknowledgments}

The authors are grateful to the National Natural Science Foundation of China (51991365), Key Special Project for Introduced Talents Team of Southern Marine Science and Engineering Guangdong Laboratory (Guangzhou) (GML2019ZD0105), Key Program of Marine Economy Development (Six Marine Industries) Special Foundation of Department of Natural Resources of Guangdong Province ([2020]047), and China Geological Survey Project (No. DD20211350).

\section{References}

[1] E. D. Sloan, "Fundamental principles and applications of natural gas hydrates," Nature, vol. 426, no. 6964, pp. 353-359, 2003.

[2] Y. Chen, S. Li, Y. Hao, and Q. Du, Theory and Technology of Natural Gas Hydrates Development, China University of Petroleum Press, Shandong, Qingdao, 2008.

[3] J. Li, J. Ye, X. Qin et al., "The first offshore natural gas hydrate production test in South China Sea," China Geology, vol. 1, no. 1, pp. 5-16, 2018.

[4] A. M. Tréhu, P. E. Long, M. E. Torres et al., "Three-dimensional distribution of gas hydrate beneath southern Hydrate Ridge: constraints from ODP Leg 204," Earth and Planetary Science Letter, vol. 222, no. 3-4, pp. 845-862, 2004.

[5] H. Zhang, H. L. Lu, J. Q. Liang, and N. Y. Wu, "The methane hydrate accumulation controlled compellingly by sediment grain at Shenhu, northern South China Sea," Chinese Science Bulletin, vol. 61, no. 3, pp. 388-397, 2016.

[6] Y. Konno, J. Yoneda, K. Egawa et al., "Permeability of sediment cores from methane hydrate deposit in the Eastern Nankai Trough," Marine and Petroleum Geology, vol. 66, pp. 487-495, 2015.

[7] S. R. Dallimore and T. S. Collett, "Intrapermafrost gas hydrates from a deep core hole in the Mackenzie Delta, Northwest Territories, Canada," Geology, vol. 23, no. 6, pp. 527-530, 1995.

[8] L. Chen, Y. C. Feng, T. Kogawa, J. Okajima, A. Komiya, and S. Maruyama, "Construction and simulation of reservoir scale layered model for production and utilization of methane hydrate: the case of Nankai Trough Japan," Energy, vol. 143, pp. 128-140, 2018.

[9] F. Chen, Y. Zhou, X. Su, G. Liu, H. Lu, and J. Wang, "Gas hydrate saturation and its relation with grain size of the hydrate-bearing sediments in the Shenhu area of northern South China Sea," Marine Geology \& Quaternary Geology, vol. 31, no. 5, pp. 95-100, 2011.

[10] L. U. Jingsheng, L. I. Dongliang, H. E. Yong, L. Deqing, and $\mathrm{X}$. Youming, "Research status of sand production during the gas hydrate exploitation process," Advances in New and Renewable Energy, vol. 5, no. 5, pp. 394-402, 2017.

[11] H. Singh, E. M. Myshakin, and Y. Seol, "A nonempirical relative permeability model for hydrate-bearing sediments," $S P E$ Journal, vol. 24, no. 2, pp. 547-562, 2019.

[12] L. Liu, S. Dai, F. Ning, J. Cai, C. Liu, and N. Wu, "Fractal characteristics of unsaturated sands - implications to relative permeability in hydrate-bearing sediments," Journal of Natural Gas Science and Engineering, vol. 66, pp. 11-17, 2019.

[13] A. Johnson, S. Patil, and A. Dandekar, "Experimental investigation of gas-water relative permeability for gas-hydratebearing sediments from the Mount Elbert Gas Hydrate Stratigraphic Test Well, Alaska North Slope," Marine and Petroleum Geology, vol. 28, no. 2, pp. 419-426, 2011.

[14] Z. A. Jarrar, R. I. Al-Raoush, J. A. Hannun, K. A. Alshibli, and J. Jung, "3D synchrotron computed tomography study on the influence of fines on gas driven fractures in sandy sediments," Geomechanics for Energy and the Environment, vol. 23, article 100105, 2020.

[15] C. Li, Q. Zhao, H. Xu, K. Feng, and X. W. Liu, "Relation between relative permeability and hydrate saturation in Shenhu area, South China Sea," Applied Geophysics, vol. 11, no. 2, pp. 207-214, 2014.

[16] H. Liang, Y. Song, Y. Chen, and Y. Liu, "The measurement of permeability of porous media with methane hydrate," Petroleum Science and Technology, vol. 29, no. 1, pp. 7987, 2011.

[17] Y. Konno, Y. Jin, K. Shinjou, and J. Nagao, "Experimental evaluation of the gas recovery factor of methane hydrate in sandy sediment," RSC Advances, vol. 4, no. 93, pp. 51666-51675, 2014.

[18] C. Lu, Y. Xia, X. Sun et al., "Permeability evolution at various pressure gradients in natural gas hydrate reservoir at the Shenhu area in the South China Sea," Energies, vol. 12, no. 19, p. 3688, 2019.

[19] M. Su, R. Yang, N. Y. Wu et al., "Structure characteristics in the Shenhu area, northern continental slope of South China Sea, and their influence on gas hydrate," Acta Geologica Sinica, vol. 88, no. 3, pp. 318-326, 2014. 
[20] Y. Dai and X. Pang, "Petroleum geological characteristics of Zhu II depression," Pearl River Mouth Basin. China Offshore Oil and Gas, vol. 13, no. 3, pp. 169-173, 1999.

[21] M. Yi, M. Guo, and L. Sun, “An experimental study on relative permeability curve for unsteady-state gas displacement by water," Natural Gas Industry, vol. 27, no. 10, pp. 92-94, 2007.

[22] S. Zhu, X. Peng, C. Li et al., "An approximation of the relative permeability and discussion on curve shapes in coalbed methane reservoirs," Chinese Journal of Rock Mechanics and Engineering, vol. 38, no. 8, pp. 1659-1666, 2019.

[23] W. Ji, "Gas water relative flow of tight sandstone gas reservoirs and its influence factors: case study of member 8 of Permian Xiashihezi Formation and member 1 of Permian Shanxi Formation in Shaan well 234-235 area of Sulige gas field in Ordos Basin," Journal of Jilin University (Earth Science Edition), vol. 49, no. 6, pp. 1540-1551, 2019.

[24] R. Akkal, H. Ramézani, M. Khodja, and S. Azzi, "Influence of the clay content and type of Algerian sandstone rock samples on water-oil relative permeabilities," Energy \& Fuels, vol. 33, no. 9, pp. 9330-9341, 2019.

[25] J. Wang, J. Zhao, Y. Zhang, D. Wang, Y. Li, and Y. Song, "Analysis of the influence of wettability on permeability in hydrate-bearing porous media using pore network models combined with computed tomography," Journal of Natural Gas Science and Engineering, vol. 26, pp. 1372-1379, 2015.

[26] T. J. Kneafsey, Y. Seol, A. Gupta, and L. Tomutsa, "Permeability of laboratory-formed methane-hydrate-bearing sand: measurements and observations using X-ray computed tomography," SPE Journal, vol. 16, no. 1, pp. 78-94, 2011.

[27] A. T. Corey, "The interrelation between gas and oil relative permeabilities," Producers Monthly, vol. 19, pp. 38-41, 1954. 